\title{
Масштабные программы развития призваны решать задачи технологического лидерства
}

Рассказывает Леонид Александрович Карпюк, генеральный директор АО «ВНИИНМ» имени академика А. А. Бочвара

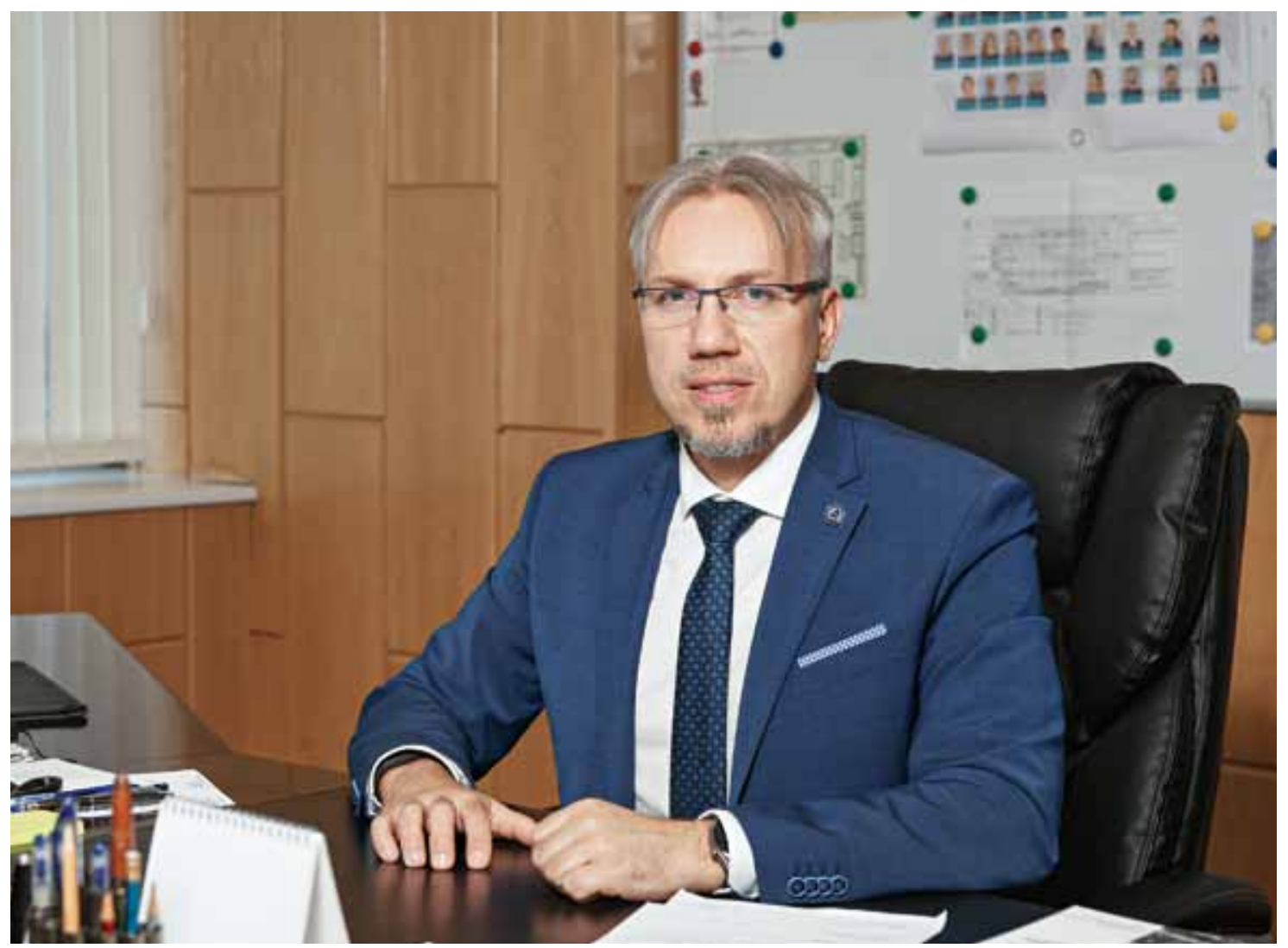

Совсем недавно, в 2020 году Высокотехнологическому научно-исследовательскому институту неорганических материалов имени академика А. А.Бочвара

(АО «ВНИИНМ») исполнилось 75 лет. Ровесник атомной отрасли в нашей стране, ВНИИНМ сегодня - один из ведущих научно-исследовательских материаловедческих центров Госкорпорации "Росатом", входит в структуру управления Топливной компании Росатома «ТВЭЛ». ВНИИНМ можно по праву назвать флагманом отечественной атомной энергетики, наукоемкого производства и технологий ядерного топливного цикла.

О новейших разработках и их внедрении в производство, способах повышения эффективности бизнеса, создании топлива нового поколения безопасности, решении важнейшей задачи замыкания ядерного цикла и переработки ядерных отходов, подготовке высококвалифицированных кадров и многом другом нам рассказал генеральный директор АО «ВНИИНМ» Леонид Александрович Карпюк. 


\section{Уважаемый Леонид Александрович! Расскажите немного об истории института.}

Институт специальных металлов (Инспецмет, НИИ-9, ныне - АО "ВНИИНМ») был создан в 1944-1945 годах прошлого столетия для решения материаловедческих и технологических проблем разработки ядерного оружия с целью ликвидации монополии США в этой области.

При активном и непосредственном участии АО "ВНИИНМ" созданы атомный флот, современные АЭС и космические аппараты. Значительную роль сотрудники ВНИИНМ и разработанные ими технологии внесли в ликвидацию последствий аварии на Чернобыльской АЭС. ВНИИНМ -

активный участник крупных международных и национальных проектов, среди которых строительство ИТЭР (Международный термоядерный экспериментальный реактор), реализация российскоамериканского соглашения "ВОУ-НОУ», создание кольцевого коллайдера будущего, замыкание ядерного топливного цикла и др.

\section{Каковы задачи и основные направления работы ВНИИНМ? Какие проекты реализуются в институте?}

ВНИИНМ традиционно выполняет функцию главного конструктора-технолога твэлов (тепловыделяющий элемент) для всех типов реакторных установок. Институт продолжает НИОКР по созданию новых и усовершенствованию действующих конструкций твэлов с урановым топливом для тепловых реакторов ВВЭР-1000, ВВЭР-440, РБМК-1000, выпускаются технические проекты твэлов новых поколений. Мы занимаемся разработкой ядерного топлива на основе диоксида урана, технологиями его изготовления и внедрением в промышленное производство; совершенствуем топливные композиции для обеспечения высоких уровней выгорания, повышения экономической эффективности и конкурентоспособности топливных циклов тепловых энергетических реакторов, в том числе топлива PWR для зарубежных потребителей. В сферу наших интересов входит разработка новых и модернизация известных циркониевых сплавов, технических требований к изделиям и технологическим процессам их изготовления, проведение дореакторных и послереакторных исследований циркониевых комплектующих для тепловыделяющих сборок (ТВС) атомных электростанций. Готовятся к внедрению новые, совершенствуются действующие технологические процессы производства конструкционных материалов тепловых реакторов АЭС. Разрабатываем разные варианты топлива нового поколения безопасности (толерантного топлива).

Качество разработанной продукции подтверждено опытом эксплуатации топлива на всех атомных станциях России, а также на АЭС Финляндии, Чехии, Словакии, Венгрии, Болгарии, Китая.

В сфере разработки твэлов для быстрых и газовых реакторов ВНИИНМ разрабатывает: топливо, твэлы, ПЭЛы и конструкционные материалы для перспективных реакторов на быстрых нейтронах с натриевым теплоносителем (типа БН); твэлы и конструкционные материалы активных зон реакторов на быстрых нейтронах с тяжелым жидкометаллическим теплоносителем (типа БРЕСТ и СВБР); совершенствуются конструкционные материалы активных зон, твэлов и ПЭЛов для реакторов БН-600, БН-800 и БН-1200; проводятся разработки твэлов на базе микросферического топлива для

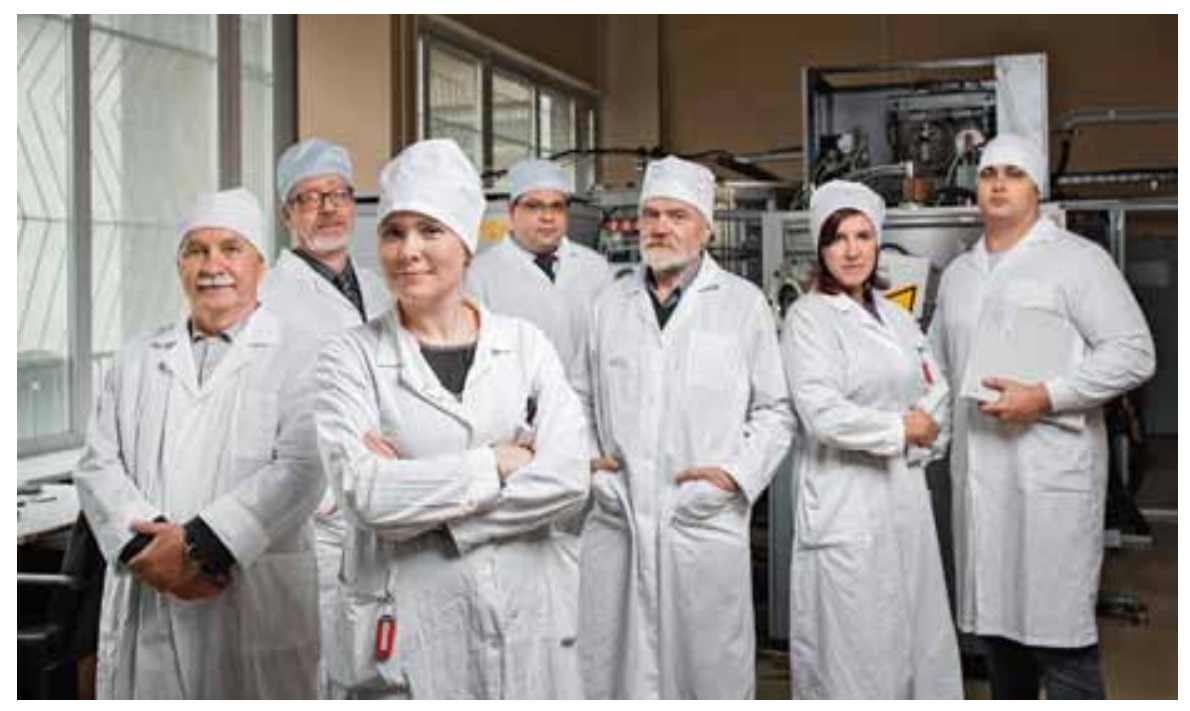


высокотемпературных газовых реакторов. Кроме того, ВНИИНМ разрабатывает твэлы и топливо для реакторов различного назначения (транспортных, промышленных и исследовательских реакторов, атомных станций малой мощности); конструкции и технологии изготовления поглощающих элементов (СВП и ПЭЛ) и пусковых источников нейтронов (ПИН).

ВНИИНМ с момента создания решает научные и технологические задачи, связанные с переработкой облученного ядерного топлива (ОЯТ) быстрых и тепловых реакторов и обращением с радиоактивными отходами (РАО), возникающими в результате переработки ОЯТ.

Сегодня ВНИиНМ разрабатывает: технологии переработки ОЯт быстрых реакторов и обращения с РАО опытно-демонстрационного энергокомплекса с пристанционным замкнутым топливным циклом (проектное направление "Прорыв"); инновационные технологические и аппаратурные решения переработки ОЯт реакторов на тепловых нейтронах на базе опытно-демонстрационного комплекса ФГУП «ГХК"; технологические переделы гидрометаллургических методов переработки ОЯт (быстрых и тепловых реакторов), включая оксидное, нитридное и металлическое ядерное топливо; высокотемпературные технологии обращения с РАО, включение PAO в стеклоподобные, минералоподобные и керамические матрицы.

В 2019 году Госкорпорация "Росатом" приступила к реализации амбициозного проекта по созданию исследовательского жидкосолевого реактора (ЖСР), который предполагается разместить на площадке ФГУП «ГХК». Научные исследования подтверждают, что ЖСР является наиболее эффективным дожигателем минорных актинидов, прежде всего америция, образующихся в ядерном топливе при эксплуатации энергетических реакторов. АО "ВНИИНМ" является организацией - научным руководителем в части топливного цикла ЖСР, то есть отвечает за разработку технологий создания топливных композиций, технологий регенерации отработавшего топлива и обращения с образующимися PAO. Успешное решение научно-технических проблем, связанных с созданием ЖСР станет важной ступенью на пути к замыканию ядерного топливного цикла.

\section{Какое достижение вы считаете наиболее зна- чимым?}

Одной из основных задач не только для ВНИИНМ, но и для отрасли является проект создания топлива нового поколения безопасности, которое получило название "толерантное" топливо. В 2021 году специалисты института ведут работы по созданию технологии и изготовлению топлива на основе дисилицида урана. В конце прошлого года впервые был получен слиток этого материала, который по нашим расчетам способен обеспечить дополнительную безопасность использования топливных композиций за счет повышенной теплопроводности и как следствие повысить экономическую эффективность АЭС. В настоящий момент отрабатывается технология изготовления таблеток из этого материала с перспективой ее масштабирования для передачи на производственную площадку в текущем году. В сентябре 2021 года на энергоблоке № 2 Ростовской АЭС (филиал концерна "Росэнергоатом") началась опытно-промышленная эксплуатация тепловыделяющих элементов нового поколения безопасности. В рамках капитального ремонта в составе партии свежего топлива в активную зону реактора ВВЭР-1000 были загружены три комбинированные тепловыделяющие сборки конструкции ТВС-2M, каждая из которых содержит по двенадцать твэлов в инновационном исполнении: шесть изготовлены с применением в качестве конструкционного материала хром-никелевого сплава 42ХНМ и еще шесть - с оболочками из циркониевого сплава 
с хромовым покрытием. Эксплуатация топлива в энергетическом реакторе - важный шаг для дальнейшей коммерциализации этого продукта.

\section{I Каковы источники финансирования проектов?}

Главным заказчиком работ для института является Топливная компания "ТВЭЛ" и Госкорпорация "Росатом", в состав которых входит АО "ВНИИНМ". Говоря об эффективности корпоративного управления, обращусь к цифрам. ВНИИНМ на протяжении последних пяти лет превышает плановые показатели по выручке. К примеру, по итогам работы в 2020 году, нам удалось заработать 5099 млн руб., что на 8\% выше плана, установленного топливной компанией. Не будет преувеличением сказать, что ВНИИНМ демонстрирует устойчивую экономическую эффективность, что говорит о правильности выбранной модели взаимодействия.

Кроме финансирования в рамках традиционных проектов по ядерному топливному циклу, развивается и стимулирование инициативных работ ученых. Три года назад в госкорпорации "Росатом" была внедрена система аванпроектов, сформирован Единый отраслевой тематический план, что позволило инициировать целый комплекс разработок по предложению ученых АО "ВНИИНМ". В настоящее время реализуется программа развития техники, технологий и научных исследований в области использования атомной энергии (РТТН), которая недавно получила продолжение и финансирование до 2030 года. В рамках реализации РТТН специалисты института занимаются разработкой так называемых кандидатных материалов на перспективу.

Сегодня устойчивого роста бизнеса невозможно достичь только за счет повышения эффективности (снижения издержек, повышения производительности труда и т. д.), хотя работу в этом направлении надо продолжать. Нужны технологические прорывы, причем не только в основном бизнесе производстве ядерного топлива и обогащенного урана - необходимо развитие новых перспективных направлений. И научно-исследовательские и опытно-конструкторские работы в этом играют ключевую роль. Такие масштабные программы развития призваны решать задачи технологического лидерства.

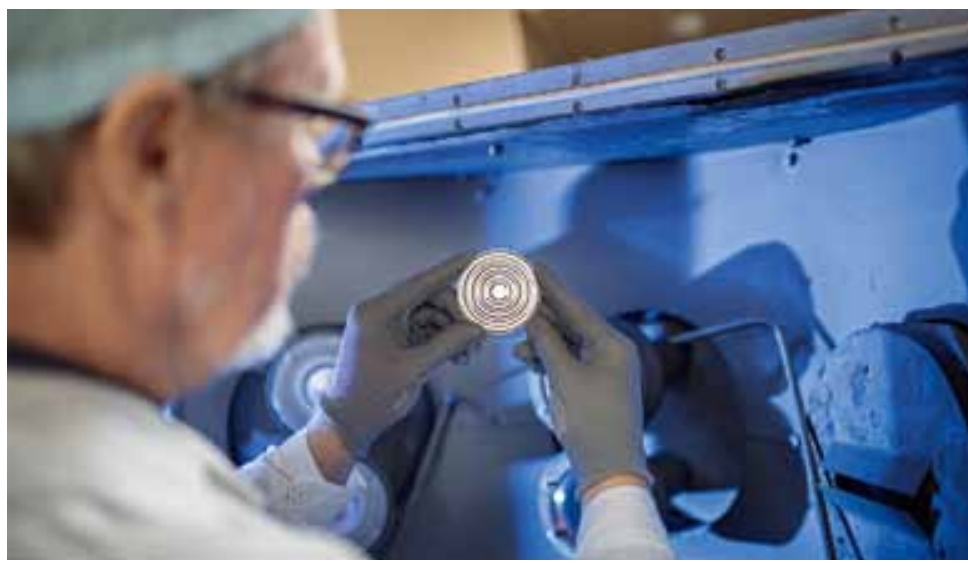

В настоящий момент во ВНИИНМ реализуется 24 инвестиционных проекта, направленных как на техническое перевооружение и модернизацию научных подразделений, так и на развитие и поддержание инфраструктуры, обеспечение безопасности института и выполнение требований законодательства. Многие из них на начальном этапе были инициативными.

\section{I Какими ноу-хау обладает институт?}

По данным на начало 2021 года, институт обладает правами на 599 новых научных разработок. АО “ВНИИНМ" в 2020 году в Российской Федерации подало десять заявок на изобретения, три заявки на полезные модели и две заявки на оформление программ для ЭВМ по переработке облученного ядерного топлива, топливным, конструкционным и функциональным материалам. Кроме того, институт направил одиннадцать международных заявок по переработке ОЯТ, конструкционным и функциональным материалам. Специалисты института получили шесть патентов на изобретения и три патента на полезные модели. В 2020 году количество оформленных ноу-хау возросло на четверть и составило 114. При выполнении научно-исследовательских и опытноконструкторских работ активно используются полученные ранее ноу-хау.

\section{| Какой инфраструктурой располагает институт?}

ВНИИНМ является Государственным научным центром и признанным лидером в области 
материаловедения и технологий ядерного топливного цикла. Специалисты института являются разработчиками подходов к повышению эффективности научных процессов на всех стадиях жизненного цикла: от идеи до запуска в производство. Инфраструктура сконцентрирована именно на обеспечении потребностей разработки наукоемкой продукции. Кроме того, ВНИИНМ - одно из немногих столичных предприятий, обладающих большой территорией, собственными опытнопроизводственными мощностями, современным исследовательским и аналитическим оборудованием, а также штатом высококвалифицированных специалистов.

\section{Какова роль института в подготовке кадров для отрасли?}

Во ВНИИНМ успешно готовят кадры высшей квалификации для предприятий "Топливной компании". Развитие технологий, материалов, оборудования и повышение качества продукции возможно при условии накопления опыта и повышения квалификации сотрудников. Это в свою очередь предполагает наряду с практической деятельностью освоение новых знаний и навыков. Аспирантура ВНИИНМ обеспечивает этот процесс, способствуя решению научнотехнических задач, стоящих перед компанией.

Сегодня институт ведет подготовку специалистов высшей квалификации по трем направлениям: «Ядерная, тепловая и возобновляемая энергетика и сопутствующие технологии", "Химические технологии" и "Технологии материалов". Всего же в аспирантуре обучаются 37 аспирантов, являющихся работниками АО «ТВЭЛ», ПАО «МСЗ», АО «ВПО Точмаш" и АО «ВНИИНМ».

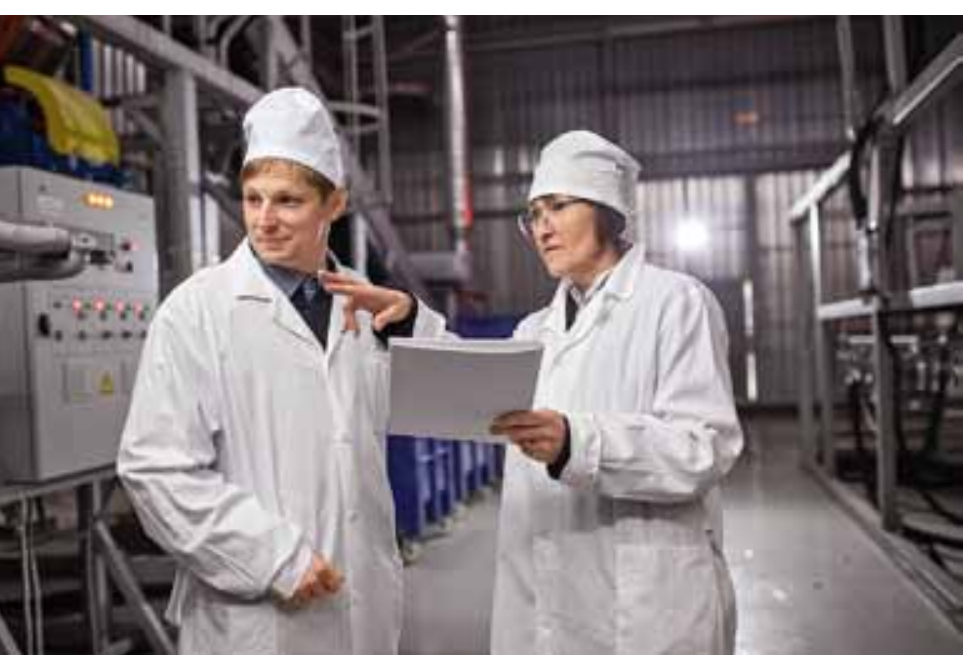

Кроме того, в 2019 году руководство Топливной компании “ТВЭЛ» и НИЯУ МИФИ согласовали пятилетнюю программу совместных научно-исследовательских и опытно-конструкторских работ НИЯу МИФИ и АО "ВНИИНМ" по совершенствованию материалов активных зон легководных реакторов на тепловых нейтронах на 2019-2023 годы. Работа направлена на научно-техническую поддержку совместной подготовки специалистов-материаловедов высшей квалификации для предприятий атомной отрасли в аспирантуре НИяу МИФИ. Совместная подготовка специалистов в области радиационного и реакторного материаловедения в НИЯу МИФИ и АО "ВНИИНМ" продолжается силами преподавателей кафедры «Физические проблемы материаловедения» МИФИ в филиале, который находится во ВНИИНМ.

\section{Как реализуется связь института с промышлен- ностью?}

Как и любой научно-исследовательский институт, ВНИИНМ специально создавался для организации научных исследований и проведения опытноконструкторских разработок в интересах промышленного производства. Как я уже упоминал, основным нашим заказчиком является Топливная компания «ТВЭЛ" и Госкорпорация "Росатом", а значит и промышленные предприятия, входящие в их состав.

\section{Как вы оцениваете состояние и перспективы развития профильных для института отрас- лей науки и промышленности в России?}

Несколько лет назад большой популярностью пользовалась фраза "ренессанс атомной промышленности". Этот тезис справедлив и сегодня. По всему миру ведется строительство атомных энергоблоков российского образца, стартуют проекты по развитию малой атомной энергетики, разрабатываются новые типы ядерных энергоустановок. Отчасти это вызвано ростом энергопотребления в мире, а также трендами к переходу на безуглеродную энергетику. Таким образом, перспективы развития этих направлений очень высоки.

\section{Каков вклад института в программу импорто- замещения?}

Во ВНИИНМ создано производство источников бетаизлучения на основе трития. Производительность большинства стадий технологического процесса позволяет изготавливать продукцию в полупромышленных масштабах. Выпущена опытная партия, которая прошла все испытания. 
На российском рынке аналогов этой разработки нет, так что у нас большой потенциал для развития .

Во ВНИИНМ созданы полупромышленные установки для отжига заготовок, насыщения источников тритием и финальной сборки. Для повышения безопасности работ при обращении с тритием создана уникальная система детритизации технологических газов методом фазового изотопного обмена. Тритий, который выходит из установки насыщения, попадает в специальный ресивер, где накапливается до определенной концентрации.

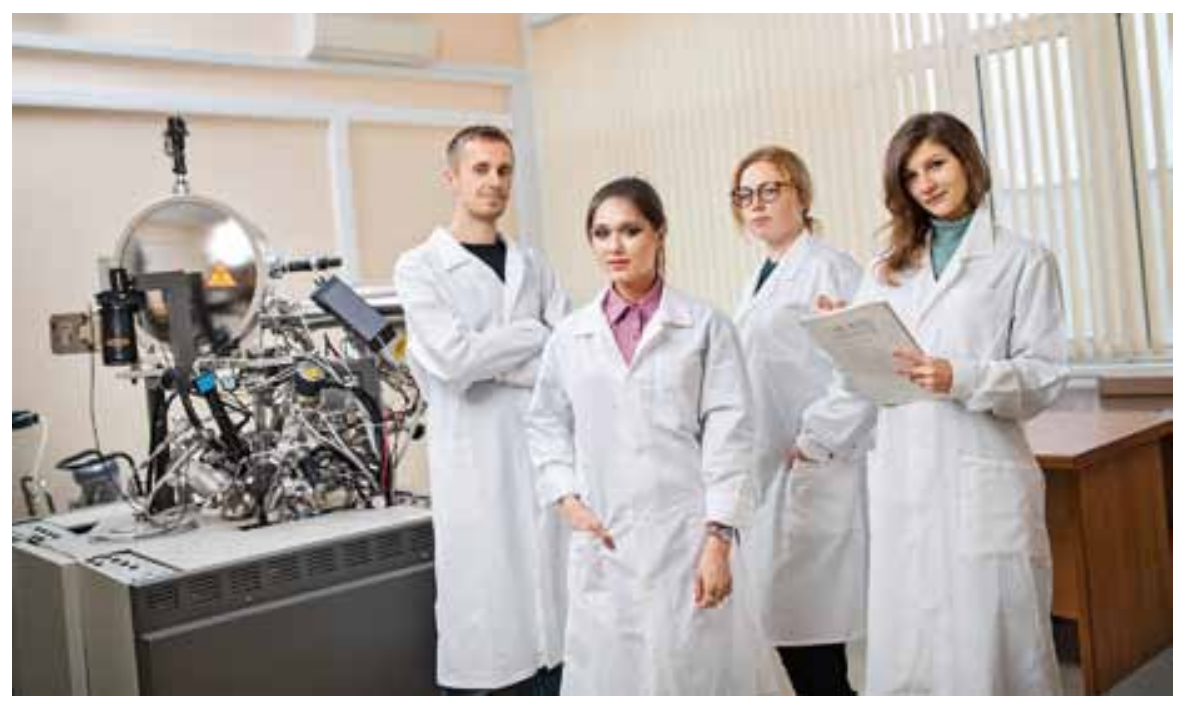
После преодоления порогового значения тритий направляется в каталитический блок, где окисляется до воды. Затем поступает в колонну фазового изотопного обмена, где пары тритированной воды переводятся в жидкость, которая затем скапливается в специальном контейнере. Затем вода поступает в емкость с сухой цементной смесью, которая затвердевает, и можно сразу передавать контейнер в специализированную организацию по обращению с РАО. Степень детритизации воздуха в установке - $10^{6}$ раз, то есть на выходе из системы поток в миллион раз чище, чем на входе.

Еще одним крупным ипортозамещающим проектом, инициированным во ВНИиНМ, стало получение первых образцов длинномерного карбидокремниевого волокна. Наши специалисты получили образцы волокна из карбида кремния (SiC-волокна), содержащие 10-12\% кислорода.

Это первый шаг к созданию бескислородного SiCволокна (с содержанием кислорода менее 5\%), который позволит ученым приблизиться к созданию тепловыделяющих элементов нового поколения на основе карбида кремния.

Дальнейшее совершенствование технологии изготовления бескислородного волокна существенно повысит жаропрочность, жаростойкость и коррозионную стойкость SiC-композита.

Институты Госкорпорации выполняют, прежде всего, прикладные работы, но некоторые изыскивают еще и возможность вести фундаментальные исследования. Как обстоят с этим дела у вниинм?

Действительно, больший объем работ приходится на прикладные НИОКР. Тем не менее, в институте реализуются и поисковые проекты. В частности,

в 2016 году был инициирован проект по созданию участка и разработке технологии изготовления твэлов из карбида кремния. В начале текущего года линия введена в эксплуатацию, она является уникальной и единственной в нашей стране. В рамках проекта отработаны технологии получения волокна из карбида кремния, изготовления образцов твэлов. Эти исследования привели к получению целого комплекса объектов интеллектуальной собственности, которые позволили развить новые компетенции материаловедения органических материалов в институте неорганических материалов. Это не может не радовать. Сейчас на рассмотрении инвестиционного комитета топливной компании находится еще семь поисковых фундаментальных НИОКР, рассчитываем на их поддержку.

\section{Насколько эффективно сотрудничество с дру- гими научно-исследовательскими учрежде- ниями, российскими и иностранными?}

Безусловно, внутри Госкорпорации "Росатом" выстроена очень тесная кооперация между предприятиями отрасли. Помимо внутриотраслевых, мы очень плотно работаем с Курчатовским институтом, институтами РАН, а также университетами и вузами - МГУ им. М. В. Ломоносова, МИФИ, РХТУ, МИСИС и рядом других. Международное взаимодействие тоже есть, но оно ограничено ввиду чувствительности наших разработок с точки зрения конкуренции.

\section{I Спасибо за интересный рассказ.}

С Л.А. Карпюком беседовали О.А. Лаврентьева и В.В. Родченкова. 